\title{
MEASURING READING STRATEGY KNOWLEDGE TRANSFER: MOTIVATION FOR TEACHERS TO IMPLEMENT READING STRATEGY INSTRUCTION
}

N Klapwijk \& C van der Walt

Stellenbosch University

Although research has shown that reading strategy instruction benefits poor readers, research also shows that teachers continue to struggle with reading strategy instruction and remain resistant to its implementation for various reasons. This article reports on the analysis of quantitative data which formed part of a larger, mixed-method study. The study, which sought to create a framework for reading strategy instruction in Grades 4 to 6 through a predominantly qualitative focus, used quantitative data to, among others, provide evidence of whether strategy knowledge transfer is measurable. This article provides evidence that strategy knowledge transfer is measurable and can, therefore, be used as motivation for teachers to implement reading strategy instruction in a sustainable fashion.

\section{INTRODUCTION}

Literacy and the consequences of being illiterate is a growing concern worldwide. South Africa, in particular, is often described as being in a 'literacy crisis'. In the Progress in International Reading Literacy Study (PIRLS) survey, which studies the reading achievement and reading behaviours and attitudes of fourth-grade students (Howie et al., 2007) South African Grade 4 learners were placed last out of 40 countries. The Western Cape Education Department's Literacy and Numeracy Strategy document refers to 'alarmingly poor literacy levels' (Department of Education, 2005: 4). South African literacy statistics further reflect that some $29 \%$ of the population is illiterate (READ, 2010). South Africa's current school curriculum, originally introduced in 1997 as Curriculum 2005 and revised in 2005 as the Revised National Curriculum Statement (RNCS), places a high premium on literacy as a means to both personal development and the nation's economic prosperity.

However, despite the good intentions of the RNCS it would seem that literacy objectives are not being met. The report of the last Grade 6 Intermediate Phase Systemic Evaluation ${ }^{\mathrm{i}}$ shows that $63 \%$ of learners scored at the 'Not Achieved' level in the Language of Learning and Teaching (LoLT) tasks (Department of Education, 2005: 78). In the Languages Learning Area, learners scored $51 \%$ for the Reading and Viewing learning outcome, and only $31 \%$ for the Thinking and Reasoning outcome. What was further noticeable in the Languages Learning Area scores is the fact that learners achieved an average of $49 \%$ in multiple choice questions, but only achieved an average of $31 \%$ for open-ended questions. This seems to indicate that where test questions do not allow some form of recognition of meaning (as is possible to a degree in multiple choice questions), learners lack sufficient understanding and 
struggle to formulate their own answers. As Langer, Bartolome, Vasquez and Lucas (1990: 464) confirm, open-ended questions allow learners 'to better reveal what and how well they understand'. Learners' scores on the Systemic Evaluation results for content subjects exhibit the same trend: for Natural Science learners scored the lowest (35\%) in Learning Outcome 1 (Scientific Investigations) which focuses on evaluating and communicating findings. The report describes this result as 'probably the result of difficulties experienced in communicating and grasping intended meanings' (Department of Education, 2005: 93).

It would seem that although proficiency in the LoLT is an obvious problem, particularly when formulating responses, learners are struggling to make meaning of texts prior to formulating answers. As Calfee (2009:xiii) states, 'the capacity to explain one's thinking is critically important in school tasks' and underlines the importance of the development of comprehension. Based on the Systemic Evaluation results, it is clear that constructing meaning from a text is a problem amongst South African learners. Dixon and Peake (2008:74) point out that 'if we are failing to teach children to comprehend what they are reading ... then critical [thinking] is unlikely to be part of the pedagogical practices of many teachers'. The question arises: how can the issue of reading comprehension be addressed in South African schools?

\section{Knowledge of reading strategies as a prerequisite for reading comprehension}

During the past 20 to 30 years, research has shown that comprehension 'can be increased significantly when it is taught explicitly' (Paris \& Hamilton, 2009:49). Pressley (2001) states that ' $[\mathrm{t}]$ he case is very strong that teaching ... students to use a repertoire of [reading] comprehension strategies increases their comprehension of text' while Snow (2002:32) states that 'because meaning does not exist in text but must be constructed from the text by the reader, instruction of how to use reading strategies is necessary to improve comprehension'.

In essence, reading strategies are the things that skilled readers use to ensure that they understand what they read. Paris, Wasik and Turner (1991:692) describe strategies as 'actions selected deliberately to achieve particular goals'. For example, when skilled readers do not understand what they read, they will stop, re-read the difficult sections and try to determine what unknown words mean before continuing reading. By stopping when they do not understand, skilled readers are monitoring their comprehension, and by re-reading difficult sections, they are using a 'fix-it strategy' (Klapwijk \& Du Toit, 2009).

There are many studies that prove the benefits of comprehension strategy instruction. For example, there are studies that show that reading strategy instruction not only improves comprehension (Palincsar \& Brown. 1984; Dole, Duffy, Roehler \& Pearson, 1991; Guthrie, 2002; Stahl, 2004; Scharlach, 2008; Spörer, Brunstein \& Kieschke, 2009), but that it also benefits other areas related to reading, such as self control and regulating while reading (Paris, Wixson \& Palincsar, 1986; Haller, Child \& Walberg, 1988). Other studies show an effect on metacognitive strategy use in L2 test performance of low-ability groups (Purpura, 1998) and improved decoding abilities (Van den Bos, Brand-Gruwel \& Aarnoutse, 1998). Combining strategy instruction with other reading instruction methods have also proven to be of value, for example in a study by Wigfield et al. (2008), who investigated the benefits of combining concept-oriented reading instruction with reading strategy instruction and traditional reading instruction. 
However, despite the existence of research that shows the benefits of reading instruction, it seems that teachers seldom teach reading strategies explicitly, thereby depriving learners of the strategies they need to think about the process of meaning making when they encounter texts. Overall it seems that little, if any, formal comprehension instruction exists in schools, and where comprehension is taught teachers generally claim that they are still not sure how to teach comprehension (Liang \& Dole, 2006:742-743) and are often not aware of existing comprehension instructional frameworks for teaching.

Research also seems to indicate that teachers have difficulty in implementing strategy instruction without professional development. The problem seems to be that teachers not only have difficulty in implementing strategy instruction without professional development, but that, while ample attention is paid to the professional development of teachers for teaching reading, little, if any, attention is paid to the professional development of comprehension instruction [own emphasis] and teachers and coaching literature continue to focus on general reading instruction (Sailors, 2008:647). According to Pressley and Beard El-Dinary (1997), teachers feel that comprehension-strategies instruction requires a considerable amount of classroom time and that teachers require a 'great deal of support to understand and implement comprehension-strategies instruction'. Block and Duffy (2008:28) agree that teaching teachers to teach comprehension is often difficult and time consuming and needs to be 'collaborative, gradual and sensitive to the changing contextual conditions in classrooms'. It would seem, therefore, that the implementation of strategy instruction not only requires intensive teacher development, but probably requires considerable change in teachers' instructional methods and approaches.

The key for teachers to make sustainable changes to their instructional methods seems to be that new implementations must adhere to specific principles, and importantly, must provide evidence that they produce results. Guskey (1986) proposes that teachers are only likely to change their beliefs and attitudes after changes in student learning outcomes are evident, while Pressley and Beard El-Dinary (1997) state that teachers will react to implementations that show clear and positive benefits or effects to learners. Sailors (2008:646) confirms that teachers 'need proof that the topics and practices ... actually work on their students'.

The purpose of this article is, therefore, to present evidence that learners are able to acquire knowledge of reading comprehension strategies. The sections that follow provide context for how knowledge of specific reading strategies was measured through the use of quantitative instruments and how the resulting data taken from these measurements were used to provide evidence that the transfer of reading strategy knowledge occurred during the intervention hard evidence to teachers of positive change in their learners to encourage the sustained implementation of reading strategy instruction.

\section{THE INTERVENTION}

\section{Background}

The results reported on in this study are part of a larger study that was designed to provide a comprehension instructional framework for Grades 4 to 6 and to identify a set of core, 'starter' strategies which could be used as a basis for future continued strategy instruction. A multitude of individual strategies has been identified and recommended for reading 
comprehension instruction over the years; these range from as many as 47 (Anderson, 1991:463) to nine (Block \& Duffy, 2008:22). However, more recent research seems to show that the trend is currently towards 'teaching fewer, rather than more' and combining strategies (Block \& Duffy, 2008:24). In designing the research intervention, the strategies recommended by acknowledged researchers in the field of strategy instruction were compared to determine which strategies are commonly recommended and to include a combination of these strategies in the study. Based on Palincsar and Brown (1984), Anderson (1991), Pressley (1998), Snow (2002) and Block \& Duffy (2008), seven reading comprehension strategies were selected to be used in the intervention (see Table 1).

During the same time that the pre-intervention data were being gathered (see PreImplementation Measurements), teachers were met in an information session about the research intervention. This session, a single session after school hours, consisted of providing the context for the intervention; a discussion of the strategies used in the intervention; a discussion of the use of the Teacher Checklist; and a booklet with additional information on the intervention strategies, lesson samples and sample hand-outs, such as story maps and summary sheets. Teachers asked for a week to prepare for their first lessons. Once they were ready to implement the intervention, the qualitative data were collected over a period of 15 weeks (two school terms) through classroom observations of their strategy instruction, unstructured discussions with teachers and samples of learners' work. During this time, teachers had ample access to support from the researcher at all times, in person or by phone or email. At the end of the 15 weeks, a second and final set of quantitative data, in the form of a Strategy-transfer Test (see Post-Intervention measurement), was collected from both the Experimental and Control group.

Table 1: Reading strategies used during intervention

\begin{tabular}{|l|l|}
\hline Reading phase & Reading strategy \\
\hline Before reading & $\begin{array}{l}\text { - Identify Text Type } \\
\text { - Identify Purpose for Reading } \\
\text { - Activating Prior Knowledge } \\
\text { - Predicting }\end{array}$ \\
\hline During reading & $\bullet$ Monitoring \\
\hline After reading & $\begin{array}{l}\text { - Clarifying } \\
\text { - Questioning } \\
\end{array}$ \\
\hline
\end{tabular}

The intervention strategies were selected to provide teachers with sufficient structure and guidance for attempting strategy instruction as a new concept, and to address all phases of the reading process, although it must be emphasised that, while the Before, During and After 'categorisation' of the reading process is used in Table 1, the three phases are merely used as a guideline for grouping reading strategies for the purposes of the intervention; the phases are not regarded as a finite view of the reading process. In essence, the Before Reading strategies aim to create a foundation for the During Reading and After Reading phases by enabling leaners to unlock the knowledge they bring to the reading process from their own contexts (Activating Prior Knowledge, and, to some extent, Predicting) while at the same time linking their 'own contextual knowledge' to a reason/motivation for reading (Identifying Purpose for 
Reading) and to the guiding characteristics of the text type - fiction or non-fiction (Identifying Text Type).

\section{Methodology}

The original mixed-methods study uses a variation of what Creswell (2003:216) calls the Sequential Transformative Strategy, by utilising three sequential data collection phases: first quantitative data were collected (before the start of the intervention) through the use of a word reading test and a cloze test (see Pre-implementation measurements) - these data were used to provide context for the participants' word recognition and comprehension abilities before the start of the intervention and to obtain measurements about reading strategies from the Experimental group (see Participants) for comparison with similar measurements after the research intervention. In the second data collection phase, which occurred during the intervention, the qualitative data (classroom observations and interviews) were collected. This was followed by the third data collection phase, which entailed a second set of quantitative data after the conclusion of the intervention (see Post-implementation measurement).

\section{Participants}

A total of 163 learners from Grades 4 to 6 participated in the original study. This article, however, reports only on the two Grade 5 classes $(n=68)$ where it was possible to use a Control group within the same grade. The school that was used for the research serves a low socio-economic status, predominantly Afrikaans-speaking community. Although instruction is provided in both Afrikaans and English Home Language, each grade level typically has two or three Afrikaans Home Language classes compared to one English Home Language class. However, during the year of the study the Grade 5 level had two English Home Language classes taught by two different teachers. Since the study was conducted in English Home Language classes, it was possible to use a Control group and gather data within the same grade level for comparative purposes both before and after the intervention. Therefore, one Grade 5 class $(n=33)$ was treated as the Experimental group and received strategy instruction during the research intervention, while the other Grade 5 class $(n=35)$ acted as the Control group and did not participate in the intervention in any way. In total, 12 formal observations were performed in the Grade 5 Experimental class. The Experimental group consisted of 18 boys and 15 girls, while the Control group comprised 22 boys and 13 girls.

\section{Instruments}

In total, four instruments were used for collecting quantitative data about and measurements from participants before and after the research intervention.

\section{Pre-implementation measurements}

Three instruments were used for gathering pre-intervention data to create a broad picture of the participants' word-recognition and comprehension abilities before the start of the intervention. The baseline data were gathered through two tests: the Burt Word Reading test ${ }^{\mathrm{ii}}$ and an age-appropriate cloze test. Both tests were used to create a view of participants' abilities independent of teachers' opinions and existing Departmental Systemic Evaluation 
Reports. Neither the tests nor their results were deemed to be an absolute evaluation of participants' word recognition or comprehension ability.

An Exploratory Test (ET) was designed and administered to the Experimental group before the start of the research intervention to obtain data for comparison of strategy knowledge transfer by the same group of learners after the completion of the research intervention. The ET was deemed 'exploratory' because the concept of reading strategy instruction was new to the research school; therefore its questions tested learners' knowledge of reading strategies before they had been exposed to reading strategy instruction by their teachers. Similarly, it was not possible to predict to what extent the teachers who participated in the research would take on the research intervention, how many strategies they would be able to train during the research period (and, therefore, how many should be included in the ET). Although the ET was not considered a pre-test (which asks the same questions as a post-test) it asked questions about most of the strategies contained in the intervention. After the implementation of the research intervention, when it was possible to create a Strategy-transfer Test (STT) based on the strategies that had been taught by teachers during the intervention, it was possible to use three measures (see Results of Post-intervention tests) from the ET for direct comparison with the same measures in the STT.

\section{Post-implementation measurement}

A reading Strategy-transfer Test (STT) was designed to measure transfer of reading strategy knowledge in the Experimental group after the completion of the intervention. The data from this test were used for two purposes: (1) for direct comparison within the Experimental group of learners' strategy knowledge before and after the research implementation by comparing the measurements from the ET with the same measurements in the STT, and (2) for comparing the STT measurements between the Experimental and Control groups to determine the extent of strategy knowledge transfer in the Experimental group. In other words, in both instances the results provided evidence of whether and to what extent transfer of strategy knowledge had taken place in the Experimental group during the intervention.

Five measurements were taken in the STT. These included identifying the text type (TT), creating a title for the text $(\mathrm{T})$, monitoring $(\mathrm{M})$, questioning $(\mathrm{Q})$ and summarisation (S). A rubric for each of the measures was created (see Table 2), with scoring based on a study by Hart and Speece (1998), but significantly simplified to cater for Intermediate Phase learners. The scoring for each measurement was designed to allow a range of answers. For measurements which effectively could be scored as 'correct' or 'incorrect', a total score of 1 (No response) to 3 (Correct answer) was used. For measurements (Questioning and Summarisation) to which answers could not always be scored as simply 'correct' or 'incorrect', a score of 1 (No response) to 5 (Answer completely relevant) was used.

The five measurements were scored as follows on the rubric: 
Table 2: Rubric for Strategy-transfer Test

\begin{tabular}{|l|c|l|}
\hline Measurement & Score & Explanation for score \\
\hline Text type (TT) & 1 & No answer \\
& 2 & Incorrect \\
& 3 & Correct \\
\hline Title (T) & 1 & No title \\
& 2 & Title present but not completely relevant to text \\
& 3 & Title relevant to text \\
\hline Questioning & 1 & No response/responses are not questions \\
(Q) & 2 & Questions present but not completely related to text \\
& 3 & Questions relevant and text based only \\
& 4 & Questions relevant and text based and knowledge based \\
& 5 & Questions relevant and knowledge based only \\
\hline Summarisation & 1 & No response/response is not a summary \\
(S) & 2 & Summary present but not completely relevant to text \\
& 3 & Summary partially captures gist/sentences directly from text \\
& 4 & Summary partially captures gist/own words used \\
& 5 & Summary accurately captures gist/own words used \\
\hline Monitoring & 1 & No answer/incorrect answer \\
(M) & 2 & Answer related to monitoring \\
& 3 & Correct answer \\
\hline
\end{tabular}

Three separate scorers were used to score the STT, and an Intraclass Correlation test was performed on their scores. Portney and Watkins' (2000) ICC agreement index was applied to the results of the correlation test and showed that, except for one measurement (Summarisation at 0.60), all scores showed a strong (0.7 - 0.8) to almost perfect agreement (> 0.8 ), thereby indicating an acceptable level of reliability.

In terms of the baseline data gathered for participants' existing word recognition and comprehension abilities, learners' real age and Burt age (as determined by the Burt Word Test) were deducted from each other to obtain learners' reading age difference. Once the reading age difference per learner had been calculated, a Mixed Model Repeated Measures ANOVA was used to determine the mean reading age difference for the grade groups that participated in the intervention. In addition to this, once learners' cloze scores had been calculated, a Pearson correlation was performed to determine whether a relationship existed between learners' cloze results and reading age difference.

A one-way ANOVA was used to compare the measurements from the ET (taken before the intervention) and STT (taken after the intervention) for the learners in the Experimental group. A comparison was done for the three measurements obtained from both tests, to provide an indication of whether transfer of strategy knowledge, as taught during the intervention, took place.

In order to report on the extent of the difference made by the intervention, Cohen's $d$ was used to perform an effect-size analysis on the ET and STT measurements to compare the differences (if any) in the Experimental group's scores before and after the research 
intervention. Thalheimer and Cook'sii (2002) calculator was used to determine the meaningfulness of the intervention portrayed as the size of the effect of the intervention, as well as the percentage of change recorded from the ET to the STT.

\section{RESULTS AND DISCUSSION}

It should be reiterated at this point that the objective of the ET and STT was to measure transfer of strategy knowledge. The objective was not to measure the effect on, or increase of, reading comprehension levels. The discussion that follows, therefore, focuses only on providing evidence of whether knowledge of strategies was transferred, since this kind of knowledge is the first step to develop and increase reading comprehension. Through the implementation of the intervention over a longer term (such as a complete school year), the ultimate goal would be to measure whether reading strategy instruction, as taught in the intervention, has an effect on participants' reading comprehension.

\section{Results of pre-intervention measurements}

The Burt Word Test results showed that $76 \%$ of participants measured a reading age that was lower than their real age, which means that the majority of learners read at a level that was generally lower than it should have been in their respective grades and for their respective ages. Once the reading age difference had been calculated for all participating learners by deducting their real age from their Burt age, a Mixed Model Repeated Measures ANOVA (n $=283, \mathrm{~F}(3,140)=18.9, \mathrm{p}<0.01)$ was used to determine the mean reading age difference (RAD) per group. The results for the Grade 5 groups are presented in Table 3.

Table 3: Mean real age and mean reading age per Grade 5 group

\begin{tabular}{|c|c|c|c|c|c|}
\hline Group & Age type & $\mathbf{N}$ & $\begin{array}{c}\text { Mean age } \\
\text { per age } \\
\text { type }\end{array}$ & $\begin{array}{c}\text { Mean } \\
\text { Standard } \\
\text { Deviation }\end{array}$ & $\begin{array}{c}\text { reading } \\
\text { age } \\
\text { difference }\end{array}$ \\
\hline $\begin{array}{c}5 \mathrm{C} \\
\text { (Control } \\
\text { group) }\end{array}$ & Real & 35 & 10.87 & 2.81 & \multirow{2}{*}{1.6} \\
\cline { 2 - 5 } & Burt & 35 & 9.27 & 2.47 & \\
\cline { 2 - 5 } & Real & 31 & 11.33 & 0.77 & \multirow{2}{*}{2.36} \\
\hline
\end{tabular}

The cloze tests were scored and an average score for each grade group calculated. However, the results showed no significant difference in the average cloze score of the respective groups, which meant that a comparison of learners' comprehension ability (as measured by the cloze test) and their word reading skills (as measured by the Burt Word Reading Test) did not seem possible.

The comparison of reading age difference (RAD) and cloze test scores, on the other hand, showed a relationship between a high RAD (weak(er) reading skills) and low cloze test scores (low(er) levels of comprehension). The low cloze score $=$ high $R A D$ trend was evident 
throughout in comparisons between individual learners' scores. The opposite also generally seemed to hold true: the strong(er) the word recognition skill (i.e. the lower the RAD), the higher the comprehension test score. However, despite the fact that the trend of a low cloze score $=$ high $R A D$ and vice versa held true for the majority of learners, there were some exceptions to both the aforementioned trends. For example, one learner with a high RAD of +5.17 (i.e. who read more than 5 years below his/her reading age) scored $78 \%$ in the cloze test, and another learner with a low RAD of -1.42 (i.e. who read more than one year above his/her reading age) scored only $34 \%$ in the cloze test. Furthermore, there were examples of learners with similar RAD values who showed vast differences in their cloze results. For example, two learners from Grade 5E both measured a negative-value RAD of -0.17 but scored $90 \%$ and $45 \%$ respectively in the cloze test.

Although the majority of learners with a (high) positive-value RAD generally obtained a low cloze score, these exceptions seem to indicate, at least as far as the data for this article are concerned, that reading comprehension is determined by more than word reading skill, and conversely, that strong word reading skills do not necessarily ensure good comprehension. Large positive reading age differences were associated with lower comprehension ability and vice versa. Furthermore, as indicated by the significant correlation of $r=-0.58, \mathrm{p}<0.01$ in the Pearson correlation, there seems to be a fairly conclusive link between poor word reading skills (as measured by the Burt Word Test) and poor reading comprehension (as measured by the cloze test). However, it is important to emphasise that word reading proficiency is not the only factor that would influence comprehension.

\section{Results of post-intervention measurement}

Although the Exploratory Test (ET) was administered before the intervention, its results were intended solely for comparison with the STT results. The ET results are, therefore, discussed as part of the post-intervention test results.

Data gathering after the intervention was done through the use of a Strategy-transfer Test (STT) which had two purposes:

- The analysis of Experimental group learners' change (if any) in strategy knowledge before and after the research implementation by comparing their scores from the Exploratory Test (ET) with the scores for the same measurements in the STT.

- Comparing the STT measurements between the Experimental and Control groups to determine the extent of strategy knowledge transfer in the Experimental group, and therefore, the overall effectiveness of the intervention.

\section{Analysis of Exploratory Test data}

As mentioned earlier, the Exploratory Test was not a formal pre-test; it was deemed to be exploratory because it was administered to the Experimental group before the research intervention, which meant that learners were asked to use strategies about which they had little or no knowledge. It, therefore, was only possible to determine which ET measurements would be useful for comparison with similar measurements from the STT data after the intervention. Upon completion of the intervention and after administering the STT, three measurements from the ET $(n=30)$ were used for comparison with the same measurements from the STT $(n=33)$ for the Experimental group. 
A one-way ANOVA was used to compare the Experimental group's ET scores for the three measurements before the intervention with their STT scores for the same measurements after completion of the intervention. Results returned a significant difference (with $p<0.01$ ) for all three measurements (S-Summarisation, M-Monitoring and Q-Questioning), indicating that the intervention had a significant effect on learners' knowledge of these measurements.

Cohen's $d$ (an effect-size analysis) was also performed on the ET and STT measurements to measure the effect (if any) of the research intervention on learners' scores before and after the research intervention. The results of the Cohen's $d$ analysis of the ET and STT measurements are displayed in Table 4.

Table 4: Effect-size analysis of Exploratory Test measurements

\begin{tabular}{|c|c|c|c|c|c|c|c|}
\hline $\begin{array}{c}\text { Measure- } \\
\text { ment }\end{array}$ & $\begin{array}{c}\text { ET } \\
\text { mean } \\
\mathbf{n = 3 0}\end{array}$ & $\begin{array}{c}\text { ET std } \\
\text { devia- } \\
\text { tion }\end{array}$ & $\begin{array}{c}\text { STT } \\
\text { mean } \\
\mathbf{n = 3 3}\end{array}$ & $\begin{array}{c}\text { STT } \\
\text { std } \\
\text { devia- } \\
\text { tion }\end{array}$ & $\begin{array}{c}\text { Cohen's } \\
\text { d effect } \\
\text { size }\end{array}$ & $\begin{array}{c}\text { Percent } \\
\text { change }\end{array}$ & F test \\
\hline Questioning & 2.3 & 1.02 & 2.9 & 0.72 & Medium & $26 \%$ & $\begin{array}{c}\mathrm{F}(1,29)= \\
19.589 \\
\mathrm{p}=.00012\end{array}$ \\
\hline $\begin{array}{c}\text { Summari- } \\
\text { sation }\end{array}$ & 2.4 & 0.96 & 3.3 & 0.99 & Large & $38 \%$ & $\begin{array}{c}\mathrm{F}(1,29)= \\
28.325 \\
\mathrm{p}=.00001\end{array}$ \\
\hline Monitoring & 1.4 & 0.68 & 2.3 & 0.73 & $\begin{array}{c}\text { Very } \\
\text { large }\end{array}$ & $64 \%$ & $\begin{array}{c}\mathrm{F}(1,29)= \\
36.282 \\
\mathrm{p}=.00000\end{array}$ \\
\hline
\end{tabular}

The results in Table 4 indicate that the intervention had a 'medium' to 'very large' effect on learners' knowledge of the three measurements taken between the ET (comparison measurement) and the STT (treatment measurement), with the largest effect being on the Monitoring measurement.

Overall, learners' knowledge of Monitoring and Summarisation skills showed the greatest improvement. The increase in knowledge of Summarisation skills can, however, be considered more representative of learners' actual increase in both knowledge and application of the Summarisation strategy than the Monitoring strategy. The scores of the Summarisation measurement were calculated by judging learners' summaries of a paragraph. In other words, learners were able to present 'hard evidence' of their application of the strategy. Monitoring, however, implies that learners are aware of whether they understand what they are reading, and if they do not understand, that they realise this and apply the appropriate strategy. Monitoring, therefore, is more difficult to measure in a written test, e.g. in the STT learners were required to answer the question "What must I ask myself while reading?" (Answer = "Whether I understand what I am reading" or anything related to checking understanding). In other words, although most learners scored well in this measurement, the score merely indicates that they were aware that they needed to check their understanding. It does not mean that they were, in fact, checking their understanding while reading. 
In terms of the Questioning measurement, there was also an increase in scores between the ET and STT. However, the increase was mostly an increase in scores at a text-based level (from 1 to 3 or 2 to 3), rather than an increase in scores from a text-based to knowledge-based level (3 to 4 or 5). As can be expected, learners whose reading age was higher than their real age showed a smaller/no increase in Questioning compared to learners who had not yet attained the age-appropriate reading level.

\section{Comment on Strategy-transfer Test measurements}

In terms of striking a balance in allocating scores for the STT, it did not seem fair to penalise learners from the Control group unnecessarily because they had not been exposed to the intervention. In scoring their responses they were, therefore, given the benefit of the doubt when the weakness in their answers was due to lack of exposure to the intervention. To level the playing field between the learners in the Control group and Experimental group, question marks were disregarded. However, where Control group answers clearly showed that learners did not know the answer, such answers were scored as incorrect. Another example includes the scoring of the Questioning strategy ( $Q$ measurement). A question, however poorly phrased, was accepted and scored as a question. This means that learners in the Control group who had not received instruction in questioning techniques, but were able to provide a question (albeit poorly phrased), sometimes scored virtually the same as learners in the Experimental group who provided a well-phrased text-based question. An example of this is found in the responses of a learner from the Control group (5C) and Experimental group (5E) respectively:

5C Learner - How was the story for you [?]

5E Learner - Why didn't Luther miss playing basketball?

Overall, the results of the analysis of the STT indicate that the research intervention had a positive effect on the Experimental group learners' knowledge of the measured strategies. While it would not normally be logical to state that a Control group did worse in a test because they were not taught the specifics of what was being tested, it is possible to allege that the intervention did make a difference, since the comparison of ET and STT results for the Experimental group shows that the learners improved relative to themselves.

\section{Analysis of Strategy-transfer Test data}

As described in the Participants section a second Grade 5 class was used as a Control group in this study in order to determine the effect (if any) of the intervention on learners who received the research intervention (the Experimental group, Grade 5E) and learners in the same grade who did not receive the intervention (the Control group, Grade 5C).

A one-way ANOVA was performed on the STT data to determine the differences, if any, between the STT scores for the Experimental and Control groups. The difference was significant (with $\mathrm{p}<0.01$ ) for the $\mathrm{S}$ (Summarisation), $\mathrm{M}$ (Monitoring) and $\mathrm{T}$ (Title) measurements, thereby indicating that the intervention had a significant positive effect on the Experimental group's knowledge of the measurements compared to their Control group counterparts. A trend (significant at 5\% level, $\mathrm{p}=0.02$ ) was visible for the Q (Questioning) measurement, indicating that the intervention had some effect on the Experimental group's 
knowledge of this strategy. The TT (Text Type) measurement showed little to no effect ( $\mathrm{p}=$ 0.38) on the Experimental group's knowledge in comparison with the Control group.

Using Cohen's $d$ an effect-size analysis was further performed to measure the size of the effect of the intervention on the group scores for each measurement.

Table 5: Effect-size analysis of Strategy-transfer Test measurements

\begin{tabular}{|c|c|c|c|c|c|c|c|}
\hline \multirow[b]{2}{*}{$\begin{array}{c}\text { Measure- } \\
\text { ment }\end{array}$} & \multicolumn{2}{|c|}{$\begin{array}{c}\text { Group 5E } \\
(n=33)\end{array}$} & \multicolumn{2}{|c|}{$\begin{array}{c}\text { Group 5C } \\
\text { (Control) } \\
(n=33)\end{array}$} & \multicolumn{2}{|c|}{ Cohen's d } & \multirow[b]{2}{*}{ F test } \\
\hline & $\mathbf{M}$ & SD & $\mathbf{M}$ & SD & $\begin{array}{c}\text { Effect } \\
\text { size }\end{array}$ & $\begin{array}{l}\text { Percent } \\
\text { change }\end{array}$ & \\
\hline Questioning & 2.90 & 0.72 & 2.42 & 0.90 & Medium & $20 \%$ & $\begin{array}{c}\mathrm{F}(1,64)= \\
5.8017 \\
\mathrm{p}=0.02\end{array}$ \\
\hline $\begin{array}{l}\text { Summari- } \\
\text { sation }\end{array}$ & 3.39 & 0.99 & 2.42 & 0.96 & Large & $40 \%$ & $\begin{array}{c}\mathrm{F}(1,64)= \\
16.031 \\
\mathrm{p}=<0.01\end{array}$ \\
\hline Monitoring & 2.33 & 0.73 & 1.54 & 0.61 & $\begin{array}{l}\text { Very } \\
\text { large }\end{array}$ & $51 \%$ & $\begin{array}{c}\mathrm{F}(1,64)= \\
22.209 \\
\mathrm{p}=<0.01\end{array}$ \\
\hline Text Type & 2.63 & 0.60 & 2.51 & 0.50 & Small & $5 \%$ & $\begin{array}{c}\mathrm{F}(1,64) \\
=.78049 \\
\mathrm{p}=0.38\end{array}$ \\
\hline Title & 2.54 & 0.50 & 2.03 & 0.72 & Large & $25 \%$ & $\begin{array}{c}\mathrm{F}(1,64)= \\
11.142 \\
\mathrm{p}=<0.01\end{array}$ \\
\hline
\end{tabular}

As is evident from Table 5, the effect of the intervention on the Experimental group's strategy knowledge seems considerable. The results show an effect size of $51 \%$ for Monitoring, $40 \%$ for Summarisation and $25 \%$ for providing a title (also a form of summarisation). As mentioned earlier, the 'very large' effect size score for the Monitoring measurement could be considered misleading, since it shows that, while learners knew they had to check their understanding, it does not provide evidence that they did in fact check their understanding. However, the results of the summarisation measurement are more telling - the scores for the S-measurement are based on learners' summaries and indicate not only that knowledge of the summarisation strategy was transferred, but that the Experimental group learners also were able to apply this knowledge.

\section{CONCLUSION}

At the start of this article we mentioned that research points to the fact that teachers seldom teach reading strategies explicitly, thereby depriving learners of the strategies that they need in thinking about the process of meaning making when they encounter texts. We also pointed out that it seems as if little, if any, formal comprehension instruction exists in schools, 
because teachers continue to find comprehension instruction difficult and time consuming, and do not always seem convinced that certain methodologies actually work.

Roberts (2010:93) points out that, ultimately, 'what is worth teaching is a matter of judgement' and 'the fact that an activity works, does not necessarily mean it is worth doing'. In other words, convincing teachers on the basis of research evidence that a new methodology is worth implementing may not necessarily be enough to ensure its sustained implementation. Teachers need very specific evidence that a new method 'works'; they need evidence that the method makes a difference to their learners.

This article provides evidence that it is possible to measure the transfer of strategy knowledge, and that having physical evidence of learners' improvement should arguably act as motivation for teachers not only to implement strategy instruction, but to do so in a sustained manner. While the aim of the measurement of strategy knowledge transfer in this study was not to provide evidence of increased reading comprehension, the learners' metaknowledge of reading strategies seems to indicate that they are ready to implement the measured reading strategies.

As far as the formal inclusion of reading strategy instruction in South African education goes, the final draft of the Department of Education's Curriculum and Assessment Policy Statement (2011:9-10) explicitly includes the use of reading strategies. While the inclusion of a focus on reading comprehension instruction is certainly a step in the right direction, concerns remain about whether comprehension is being addressed adequately in schools, and whether teachers have the requisite training to teach comprehension as part of reading instruction. Sailors (2008:652) points out that there still seem to be no studies about the professional development of teachers and comprehension instruction, and new teachers still enter schools 'with the understanding of how to teach comprehension ... based on how they were taught to read'. Providing evidence of how learners become familiar with reading comprehension strategies is a necessary first step to encourage teachers to take a first step in teaching comprehension strategies, thereby increasing the possibilities of improved comprehension.

\footnotetext{
${ }^{\mathrm{i}}$ The Intermediate Phase Systemic Evaluation is performed every three years. The most recent evaluation was conducted in 2009. Results were not available at the time of writing this article.

ii The Burt Word Test is used on learners of 6 to 13 years. The Test consists of 110 words printed in decreasing size and increasing difficulty. The words are read out loud by one learner at a time without help from the test administrator. Once the learner has misread or failed to read 10 consecutive words, the test is stopped and the number of correctly read words added together to obtain a total out of 110. The learner's Burt Age is determined by using the Burt Word Reading Test rubric.

iii Thalheimer and Cook (2002), whose spreadsheet calculator was used in this article, utilise the following effect-size scale for the relative size of Cohen's $d$ :

Negligible effect $(\geq-0.15$ and $<.15)$ Small effect $(\geq .15$ and $<.40)$ Medium effect $(\geq .40$ and $<.75)$

Large effect $(\geq .75$ and $<1.10)$ Very large effect $(\geq 1.10$ and $<1.45)$ Huge effect $(>1.45)$
}

\section{REFERENCES}

ANDERSON, NJ. 1991. Individual differences in strategy use in second-language reading and testing. Modern Language Journal, 75(4):460-472. 
BLOCK, CC \& GG Duffy. 2008. Research on teaching comprehension: Where we've been and where we're going. In Block, CC \& SR Parris (eds), Comprehension Instruction: Research-based best practices. New York: The Guilford Press.

CALFEE, RC. 2009. Foreword. In Israel, SE \& GG Duffy (eds), Handbook of research on reading comprehension. New York: Routledge.

CRESWELL, JW. 2003. Research design: Qualitative, quantitative and mixed method approaches. Thousand Oaks: Sage Publications.

DEPARTMENT OF EDUCATION. 2005. Grade 6 Intermediate Phase Systemic Evaluation Report, December 2005. Pretoria: Government Printer.

DEPARTMENT OF EDUCATION. 2011. Curriculum and Assessment Policy Statement. Pretoria: Government Printer.

DIXON, K \& K PEAKE. 2008. Straight for English: Using school language policy to resist multilingualism. English Teaching: Practice and Critique, 7(1):73-90.

DOLE, JA, GG DUFFY, LR ROEHLER \& PD PEARSON. 1991. Moving from the old to the new: Research on reading comprehension instruction. Review of Educational Research, 61(2):239-264.

GUSKEY, TR. 1986. Staff development and the process of teacher change. Educational Researcher, 15(5):5-12.

GUTHRIE, JT. 2002. Preparing students for high-stakes test taking in reading. In Farstrup, $\mathrm{AE} \&$ SJ Samuels (eds), What research has to say about reading instruction. Newark: International Reading Association.

HALLER, EP, DA CHILD \& HJ WALBERG. 1988. Can comprehension be taught? A quantitative synthesis of 'metacognitive' studies. Educational Researcher, 17(9):5-8.

HART, ER \& DL SPEECE. 1998. Reciprocal teaching goes to college: Effects for postsecondary students at risk for academic failure. Journal of Educational Psychology, 90(4):670-681.

HOWIE, S, E VENTER, S VAN STADEN, L ZIMMERMAN, C LONG, V SCHERMAN \& E ARCHER. 2007. PIRLS 2006 Summary Report South African Children's Reading Literacy Achievement. Pretoria: University of Pretoria.

KLAPWIJK, NM \& RO DU TOIT. 2009. Improving second-language reading comprehension through a blended-learning approach to strategy instruction. Mousaion, 29(2) SPES:77-92.

LANGER, JA, L BARTOLOME, O VASQUEZ \& T LUCAS. 1990. Meaning construction in school literacy tasks: A study of bilingual students. American Educational Research Journal, 27(3):427-471.

LIANG, LA \& JA DOLE. 2006. Help with teaching reading comprehension: Comprehension instructional frameworks. The Reading Teacher, 59(8):742-753.

PALINCSAR, AS \& AL BROWN. 1984. Reciprocal teaching of comprehension-fostering and comprehension-monitoring activities. Cognition and Instruction. 1(2):117-175.

PARIS, SG, KK WIXSON \& AS PALINCSAR. 1986. Instructional approaches to reading comprehension. Review of Research in Education, 13:91-128. 
PARIS, SG, BA WASIK \& JC TURNER. 1991. The development of strategic reading. In Barr, R, ML Kamil, PB Mosenthal \& PD Pearson (eds), Handbook of Reading Research Volume II. New Jersey: Lawrence Erlbaum.

PARIS, SG \& EE HAMILTON. 2009. The development of children's reading comprehension. In Israel, SE \& GG Duffy (eds), Handbook of Research on Reading Comprehension. New York: Routledge.

PRESSLEY, M \& P BEARD EL-DINARY. 1997. What we know about translating comprehension-strategies instruction research into practice. Journal of Language Disabilities, 30(5):486-488.

PRESSLEY, M. 1998. Comprehension strategies instruction. In Osborn, J \& F Lehr (eds), Literacy for all: Issues in teaching and learning. New York: The Guilford Press.

PRESSLEY, M. 2001. Comprehension instruction: What makes sense now, what might make sense soon. Reading Online, 5(2) [Online]. Available:

http://www.readingonline.org/articles/art_index.asp?HREF=/articles/handbook/pressley lindex.html [2010, October 11].

PORTNEY, LG \& MP WATKINS. 2000. Foundations of clinical research: Applications to practice. New Jersey: Prentice Hall Health.

PURPURA, JE. 1998. Investigating the effects of strategy use and second language test performance with high- and low-ability test takers: A structural equation modeling approach. Language Testing, 15(3):333-379.

READ Educational Trust. 2010. [Online]. Available: http://www.read.org.za. [2010, October 12].

ROBERTS, M. 2010. What is 'evidence-based practice' in Geography education? International Research in Geographical and Environmental Education, 19(2):91-95.

SAILORS, M. 2008. Improving comprehension instruction through quality professional development. In Israel, SE \& GG Duffy (eds), Handbook of Research on Reading Comprehension. New York: Routledge.

SCHARLACH, TD. 2008. Start comprehending: Student and teachers actively reading text. The Reading Teacher, 62(1):20-31.

SNOW, C. 2002. Reading for understanding: Toward an $R \& D$ program in reading comprehension. Santa Monica: Rand Reading Study Group.

SPÖRER, N, JC BRUNSTEIN \& U KIESCHKE. 2009. Improving students' reading comprehension skills: Effects of strategy instruction and reciprocal teaching. Learning and Instruction, 19(3):272-286.

STAHL, KAD. 2004. Proof, practice and promise: Comprehension strategy instruction in the primary grades. The Reading Teacher, 57(7):598-609.

THALHEIMER, W \& S COOK. 2002. How to calculate effect sizes from published research: A simplified methodology [Online]. Available: http://www.worklearning.com/effect_sizes.htm [2010, March 25].

VAN DEN BOS, KP, S BRAND-GRUWEL \& CAJ AARNOUTSE. 1998. Text comprehension strategy instruction with poor readers. Reading and Writing: An Interdisciplinary Journal, 10(6):471-498. 
WESTERN CAPE EDUCATION DEPARTMENT. 2006. WCED Literacy and Numeracy Strategy 2006 - 2016. Provincial Government Printer.

WIGFIELD, A, JT GUTHRIE, KC PERENCEVICH, A TABOADA, SL KLAUDA, A MCRAE \& P BARBOSA. 2008. Role of reading engagement in mediating effects of reading comprehension instruction on reading outcomes. Psychology in Schools, 45(5):432-445.

\section{BIOGRAPHICAL NOTE}

Nanda Klapwijk is a postdoctoral research fellow in the Department of Curriculum Studies. E-mail address: nklapwijk@sun.ac.za.

Christa van der Walt lectures and trains English language teachers in the Department of Curriculum Studies. Her interests focus on the teaching and place of English in multilingual education contexts. E-mail address: cvdwalt@sun.ac.za. 